\section{Martha C. Nussbaum, La tradición cosmopolita. Un noble e imperfecto ideal (Paidós, Barcelona, 2020) Traducción: Albino Santos Mosquera}

La traducción al español del último libro de Martha Nussbaum nos ofrece una magnífica oportunidad para aproximarnos al pensamiento de una de las filósofas más reconocidas de la actualidad, con relevantes contribuciones a la filosofía del derecho y la filosofía política. La presente obra busca estudiar y analizar críticamente la tradición del cosmopolitismo a lo largo de la historia.

El núcleo del ideal cosmopolita vendría definido, nos indica Nussbaum en el capítulo 1, por la afirmación del valor de la dignidad humana con independencia de la procedencia geográfica o social de las personas. A partir de este análisis, la autora reflexiona sobre la relevancia de esta tradición de pensamiento en relación con los problemas de nuestro mundo globalizado actual, y en particular señala su preocupación por fundamentar de un modo más eficaz y riguroso los derechos humanos de contenido social y económico, que permita su protección a escala global.

De este modo, en el capítulo 2 se examinan los inicios del cosmopolitismo en la filosofía estoica, tomando como referencia la importante figura de Cicerón. El estudio del gran jurista no solo se justifica por sus aportaciones teóricas, sino también debido a la profunda vertiente práctica de su vida, pues Cicerón no se limitó a construir castillos en el aire, sino que dedicó sus esfuerzos a la protección de la libertad romana frente a las amenazas que se cernían sobre ella.
El análisis de Nussbaum se centra en la concepción ciceroniana de los deberes de justicia y los de ayuda material, a partir de la lectura de su obra De officiis. Nussbaum muestra que, si bien Cicerón logra desarrollar un planteamiento ético sobre los deberes que sitúa la dignidad de la persona en el centro, su entendimiento de la naturaleza de estos deberes, el alcance en su aplicación y su exigibilidad presentan carencias importantes, debido sobre todo a la distinción rígida que Cicerón establece entre los deberes de justicia y los de ayuda material, atribuyendo a los segundos una jerarquía inferior y mayores condiciones para su exigibilidad, y limitando su mayor beneficio a las personas con las que se tienen lazos más estrechos. Cicerón comienza diciendo que esos deberes también son básicos para la naturaleza humana, pero con muchas salvedades y restricciones. Tenemos que asegurarnos de que nuestros dones no causen daño; tenemos que asegurarnos asimismo de que no nos empobrezcamos dándolos; y tenemos que asegurarnos de que el don es adecuado al estatus de quien lo recibe (p. 41).

Nussbaum argumenta que la separación estricta entre los dos tipos de deberes no es sostenible y ataca algunos de los criterios más utilizados en este sentido. Destaca su crítica a la concepción de los deberes de justicia como esencialmente negativos y de los de ayuda material como esencialmente positivos, ya que, recuerda, hasta el proteger a las personas de posibles ataques cuesta dinero. Nussbaum rechaza asimismo la defensa ciceroniana de los derechos de propiedad como límite a la redistribución y objeta a la pretensión del jurista romano de restringir el alcance de la eficacia de los deberes de ayuda material solo a la comunidad política par- 
ticular, si bien termina reconociendo que fuera de los límites de esta se hace más difícil la asignación de responsabilidades para satisfacer estos deberes. La conclusión inevitable es que, pese a lo que el enfoque ciceroniano tiene de aprovechable, necesita correcciones.

El estudio del estoicismo se completa con el capítulo 3, en el que Nussbaum discute las implicaciones del concepto de dignidad humana de los estoicos, en particular en la obra del emperador Marco Aurelio. Según la autora, un aspecto de la doctrina estoica que fue un obstáculo para una definición más positiva de los deberes de ayuda material fue la insistencia en que la miseria y la pobreza no constituyen percances que deban inquietar al sabio, al hombre virtuoso. Aunque tal apreciación se justifica por la necesidad de elevar moralmente al ciudadano corriente y a los más desfavorecidos, de manera que su dignidad no dependiera de sus posesiones, la realidad es que, como argumenta Nussbaum, lo material y lo económico son medios imprescindibles para la defensa de la dignidad. No basta con proclamar la capacidad moral de las personas. Si esa capacidad no nos permite conseguir lo que queremos o llevar el tipo de vida que deseamos, ¿qué nos queda? La reivindicación estoica de la dignidad humana, aunque meritoria, no sirve para fundamentar una concepción ética que permita a todas las personas el acceso a los bienes indispensables para que dicha dignidad sea efectiva.

En el capítulo 4, Nussbaum analiza las importantes contribuciones de Hugo Grocio, quien incorpora la tradición estoica al mundo moderno. En una de las secciones más logradas del libro, Nussbaum muestra cómo las teorías de Grocio permiten defender un cierto concepto de la dignidad y los derechos humanos de un modo compatible con la soberanía nacional de los Estados, sobre la base de unos principios de justicia que, no estando limitados por las fronteras ni por las diferencias religiosas, sirven para articular una comunidad internacional donde la guerra y las actuaciones unilaterales de los Estados estén sometidas a reglas morales.

De este modo, la principal aportación de Grocio será su defensa de una cierta noción de orden moral global que Nussbaum no duda en considerar como precursora del derecho internacional moderno. Frente a la pretensión de someter a los pueblos a un proyecto imperial o a un despotismo teológico, Grocio reivindicará su derecho a dotarse de leyes propias aun en contra del criterio de otros pueblos sobre lo bueno y lo justo. Naturalmente, esta idea no puede recuperarse en la actualidad tal y como Grocio la expuso, puesto que el jurista holandés no poseía una concepción moderna de la democracia y los derechos humanos, y bajo su esquema sería aceptable que un Estado adoptara medidas de carácter autoritario contra su población que hoy son indefendibles. La obra de Grocio nos revela la tensión inherente al modelo de orden internacional basado en la soberanía de los Estados, que sigue sin resolverse en la actualidad: ¿cómo garantizar el respeto a los derechos humanos sin intervenir en los asuntos internos de un Estado soberano? La clave está en la reivindicación que hace Grocio de la autonomía moral del individuo como fuente de legitimidad del poder: aunque no extrae todas las consecuencias que podrían deducirse de ello, el terreno ya ha quedado abonado para una apuesta sólida por la libertad moral de la persona y la tolerancia. 
Desde la teoría de Grocio es posible avanzar hacia una concepción de los deberes de ayuda material que trascienda los límites nacionales. Los dos puntos clave de este aspecto de su pensamiento son su idea del carácter común de ciertos bienes, como los mares, de forma que ningún Estado ni particular puede legítimamente pretender apropiarse de ellos con carácter exclusivo, y su reconocimiento de que existen situaciones de necesidad que justifican, por ejemplo, la migración a otros países e imponen deberes de acogida a los Estados en estos casos. Unas reflexiones que representan un primer paso para una teoría cosmopolita más depurada.

El análisis histórico de las principales figuras del pensamiento cosmopolita concluye en el capítulo 5, dedicado a las aportaciones de Adam Smith. El filósofo escocés es el autor de dos influyentes tratados, La riqueza de las naciones y la Teoría de los sentimientos morales, y en ambos se apoya Nussbaum para avanzar su interpretación de sus ideas. Si bien tradicionalmente se consideró que el mensaje central de La riqueza de las naciones era el descubrimiento de las leyes del mercado, Nussbaum nos muestra, en línea con los análisis más recientes, que Smith tenía hondas reservas hacia la idea de un capitalismo desenfrenado con la que su nombre ha quedado asociado en el imaginario popular. Se nos revela como un pensador con una profunda sensibilidad social. Sus teorías económicas hay que entenderlas teniendo en cuenta su inquietud por aliviar la situación de los trabajadores y de los más desfavorecidos. De ahí sus críticas a la influencia desmedida de los patrones en política, origen de graves injusticias y adulteraciones del mercado. Nada más lejos del pensamiento de Smith que la defensa de un Estado abstencionista.

El escocés corregirá uno de los defectos flagrantes del estoicismo clásico. Frente a la minusvaloración de los medios materiales que observábamos en el pensamiento de Marco Aurelio, Smith reivindicará la necesidad de que el Estado proporcione a sus ciudadanos un nivel mínimo de bienestar, y no solo sobre la base de argumentos de utilidad dirigidos a preservar la paz social, sino por una cuestión de justicia. Sus reflexiones en esta materia le llevan incluso a proponer, con carácter revolucionario para la época, la intervención del Estado en la educación, apuntando a la ignorancia como una causa de menoscabo de las facultades de las personas y, por ende, de su capacidad efectiva para llevar a cabo sus proyectos vitales. También son de interés las ideas de Smith sobre el comercio internacional: desafiando de nuevo el mito que lo estigmatiza como apologista de la clase capitalista, el escocés realiza aportaciones muy meritorias sobre la inhumanidad del colonialismo y las prácticas monopolísticas que perjudican a la mayoría en beneficio de las grandes corporaciones.

El enfoque de Smith, sin embargo, no está exento de críticas y carencias. En especial, su tratamiento de los deberes de ayuda material en la Teoría de los sentimientos morales es, a juicio de Nussbaum, claramente insatisfactorio, y ello porque parece apreciarse una contradicción evidente entre la posición que adopta en este libro y la que defiende en La riqueza de las naciones. En la Teoría de los sentimientos morales encontramos a un Smith inmerso en la filosofía estoica más clásica, que retorna a la distinción tradicional entre justicia y beneficencia y vuelve a hacer 
suyo el reproche hacia la preocupación por los bienes materiales.

Con los capítulos anteriores ha quedado concluida la exposición de las ideas fundamentales de la tradición cosmopolita. La pregunta clave, por supuesto, es la que nos hacíamos al comienzo: ipuede esta tradición aportar soluciones a los graves desafíos que enfrenta el mundo globalizado actual? Nussbaum dedica el capítulo 6 a tratar de responder a este interrogante, analizando diversas problemáticas recientes para determinar en qué medida el ideal cosmopolita puede arrojar luz sobre ellas.

En este sentido, nuestra autora realiza interesantes consideraciones sobre la aplicabilidad del marco político liberal en la concepción avanzada por John Rawls a otras culturas distintas de la occidental, para proporcionar una base común de entendimiento que permita progresar en la solución de los problemas globales. Nussbaum defiende la posibilidad de esta base común, y para ella el núcleo fundamental que todas las tradiciones pueden aceptar es el concepto político de la igual dignidad humana de todas las personas. Sin embargo, también destaca que los límites impuestos por el propio marco liberal (en el que, como proclamó Rawls, no se parte de la validez de una noción concreta de la vida buena) obligan a rechazar determinada versión del cosmopolitismo que lo plantea como una doctrina ética omnicomprensiva superadora de las ya existentes en cada país y cultura. La idea no es, pues, sustituir una ética por otra, sino encontrar aquel mínimo acuerdo en el que todas las éticas confluyen, y que será el que permitirá fundamentar una base común de diálogo y actuación.

Este mismo criterio lo aplica Nussbaum a la espinosa cuestión de cómo hacer cum- plir los derechos humanos en el mundo sin interferir en la soberanía de los Estados. Aun reconociendo la relativa falta de cumplimiento efectivo de muchas disposiciones promulgadas sobre esta materia, Nussbaum entiende que es más beneficioso insistir en ello mediante normas persuasivas y no a través de intervenciones coactivas. Debe superarse, en consecuencia, una concepción excesivamente idealista del derecho internacional.

Nussbaum tampoco rehúye el problema de la ayuda al desarrollo. Hoy no es posible acometer este análisis sin tener en cuenta las aportaciones de la ciencia económica, y en concreto Nussbaum se refiere a las importantes contribuciones del Premio Nobel de 2015 Angus Deaton, cuya investigación muestra cómo determinadas formas de implementar esta ayuda son ineficaces y no proporcionan el resultado deseado. Una vez más, el realismo es la conclusión inevitable: aunque hayamos podido argumentar de forma convincente a favor de unos deberes de ayuda material a escala global, de nada sirve si no somos capaces de llevarlos a la práctica. Lo más eficaz, nos dice Nussbaum, es facilitar el fortalecimiento de las instituciones democráticas en los países receptores de la ayuda, pues unas instituciones sólidas son la mejor garantía de una política redistributiva exitosa. En conjunto, la tradición cosmopolita permite afrontar todos los problemas mencionados, aunque necesita correcciones y adaptaciones a la sensibilidad contemporánea.

Finalmente, y como conclusión de la obra, el capítulo 7 nos introduce en el enfoque de las capacidades, que es, como ya hemos mencionado, la gran contribución de Nussbaum a la filosofía ética, y el instrumento que la autora propone para canalizar la aplicación práctica de las ideas cos- 
mopolitas. En este punto se aprecia una de las innovaciones más importantes del tratamiento de Nussbaum de estos asuntos, ya que, a diferencia de los autores de la tradición que ella reivindica, su enfoque de las capacidades apunta al reconocimiento de una cierta dignidad de los animales. La idea de justicia se convierte así en algo no solamente horizontal, por así decirlo (es decir, extensible al conjunto del planeta), sino también vertical (aun cuando este calificativo no sea del todo apropiado, ya que no hay animales inferiores ni superiores a otros en el sentido evaluativo del término), pues se extiende a las profundidades de los océanos y las alturas de nuestros cielos, y abarca a muchas criaturas diferentes (p. 267).

La lectura de este libro nos sugiere reflexiones de gran calado y también algunos interrogantes nada desdeñables. Nussbaum ha realizado una extraordinaria aportación al debate entre las exigencias del cosmopolitismo y las demandas de la nacionalidad, defendiendo, de un lado, la necesidad de una fundamentación más rigurosa de los deberes y derechos de contenido social y económico que permita su protección en todo el mundo, y de otro lado, una concepción de la gobernanza global en la que el respeto a los derechos humanos pueda ser compatible con el mantenimiento de la cultura propia de cada pueblo, evitando su aniquilación. Lo más destacable de su propuesta es el modo en el que logra armonizar unas elevadas aspiraciones filosóficas con un realismo muy marcado en cuanto a las vías de implementación de su proyecto. Aun siendo conscientes de las dificultades que entraña el cosmopolitismo y de la necesidad de reconciliarlo con la legítima defensa de la soberanía nacional, no cabe duda de que el primer paso para una globalización más justa y humana es recuperar el valor de esta tradición de pensamiento y debatir sus implicaciones para los desafíos de hoy. Nussbaum ha realizado una contribución de altura que a buen seguro suscitará una fructífera y sana controversia.

Antonio Mesa León

Universidad de Sevilla, Sevilla, España anmele@gmail.com https://orcid.org/0000-0002-2443-1548 